\title{
COMPARISON OF PLAIN ROPIVACAINE WITH ROPIVACAINE PLUS DEXAMETHASONE IN SCALP NERVE BLOCKS IN PATIENTS UNDERGOING SUPRATENTORIAL CRANIOTOMY UNDER GENERAL ANAESTHESIA: A RANDOMISED CONTROL TRIAL
}

\author{
Annapurna Sarma $B^{1}$, Murali Krishna $B^{2}$, Krishna Chaitanya $B^{3}$ \\ ${ }^{1}$ Associate Professor, Department of Anaesthesiology, Andhra Medical College, Visakhapatnam. \\ 2Professor, Department of Anaesthesiology, Andhra Medical College, Visakhapatnam. \\ 3Senior Resident, Department of Anaesthesiology, Andhra Medical College, Visakhapatnam.
}

\begin{abstract}
\section{BACKGROUND}

Pain during intra-operative and post-operative period of intracranial surgery causes severe fluctuations in haemodynamics, which can be detrimental for patients with compromised intracranial compliance. With scalp block, the sensory nerve fibres from the scalp and pericranial areas by using local anaesthetics and various adjuvants can reduce total anaesthetic requirement enabling early recovery and also reducing post-operative analgesic requirements.
\end{abstract}

\section{AIM}

To compare the effects of adding Dexamethasone to Ropivacaine and comparing its efficacy with plain Ropivacaine in providing adequate analgesia and post-operative analgesia, time of emergence from anaesthesia as well as incidence of side effects.

\section{MATERIAL AND METHODS}

180 adult patients posted for craniotomy were divided randomly into two groups, Group R and Group D. Patients of Group R received scalp block with $0.2 \%$ Ropivacaine plus saline and patients of Group D received scalp block with $0.2 \%$ Ropivacaine plus 8 mg Dexamethasone after induction. Significant elevation in heart rate, blood pressure intraoperatively, intraoperative analgesic requirements, VAS scores at 1, 4, 8, 12 and 24 hours postoperatively and incidence of post-operative complications if any were recorded.

\section{RESULTS}

There was no statistically significant difference between the mean duration of scalp nerve block in both the groups, intraope rative haemodynamic changes, intraoperative Fentanyl requirements or duration of postoperative analgesia. However, VAS scores were higher in the patients of Group R compared to Group D, but there was no significant difference in the dose of intravenous Fentanyl for postoperative pain relief. There was no significant difference in the incidence of PONV. Intraoperative hyperglycaemia was noted in 2 patients of Group D, but sugar levels normalised by the end of the surgery.

\section{CONCLUSION}

The addition of $8 \mathrm{mg}$ Dexamethasone to $0.2 \%$ Ropivacaine in scalp nerve block after induction of general anaesthesia for patients undergoing supratentorial craniotomy for intracranial space occupying lesion does not prolong the duration compared to plain $0.2 \%$ Ropivacaine, nor does decreased intraoperative Fentanyl requirements. There was also no difference in the time of emergence from anaesthesia or incidence of PONV.

\section{KEYWORDS}

Craniotomy, Scalp Block, Ropivacaine, Dexamethasone.

HOW TO CITE THIS ARTICLE: Sarma AB, Krishna MB, Chaitanya KB. Comparison of plain ropivacaine with ropivacaine plus dexamethasone in scalp nerve blocks in patients undergoing supratentorial craniotomy under general anaesthesia: a randomised control trial. J. Evolution Med. Dent. Sci. 2016;5(61):4268-4271, DOI: 10.14260/jemds/2016/974

\section{INTRODUCTION}

Anaesthesia for neurosurgical procedures needs a prudent balance of Intracranial tension, Cerebral Metabolic Rate and blood supply. The need for cautious fluid management to minimise rise in intracranial blood volume, while promptly replacing lost fluids due to diuresis, while devising a strategy

Financial or Other, Competing Interest: None.

Submission 06-05-2016, Peer Review 17-07-2016,

Acceptance 23-07-2016, Published 30-07-2016.

Corresponding Author:

Dr. Krishna Chaitanya $B$,

Door No. 48-5-52, Srinagar,

Visakhapatnam-530016,

Andhra Pradesh.

E-mail: krrish22002@gmail.com

DOI: $10.14260 /$ jemds/2016/974 for post-operative pain management instituting optimal analgesia with minimal sedation, nausea and respiratory depression pose a tremendous task to neuroanaesthesiologist. The non-uniform distribution of pain fibres in CNS causes large fluctuations in BP, heart rate during intracranial surgery. Head holders such as Mayfield head holder, which hold the head by the application of metallic pains deep into the pericranium cause severe noxious stimulus and result in haemodynamic changes. Such haemodynamic effects can be detrimental for patients with ruptured intracranial aneurysms, intracranial hypertension and cardiac morbidities, especially if the patient has compromised intracranial compliance.[1,2] De Benedittis undertook a pilot study to assess prevalence of pain in postoperative craniotomy patients and reported an incidence of $60 \%$ for moderate-to-severe pain.[3] 
Since pain during craniotomy and in post-operative period are due to a large extent from scalp and pericranial muscles, blocking the sensory nerve fibres from these areas can reduce total anaesthetic requirement enabling early recovery and also reducing post-operative analgesic requirements.[4] Girvin was the first to describe the scalp block technique in awake craniotomy in 1986.[5]

\section{AIM}

To study effect of adding Dexamethasone as adjuvant to local anaesthetic Ropivacaine in scalp nerve blocks in patients undergoing supratentorial craniotomy under general anaesthesia.

\section{OBJECTIVES}

1. Compare duration of post-operative analgesia provided by Ropivacaine plus Dexamethasone with plain Ropivacaine.

2. Compare intraoperative analgesic requirements.

3. Compare time of emergence from general anaesthesia.

4. Compare incidence of post-operative nausea and vomiting.

\section{MATERIAL AND METHODS}

The study was carried out in 3 neurosurgery operation theatres and Neurosurgery ICU in King George Hospital, Visakhapatnam. After obtaining informed consent, 180 adult patients (Age $>18$ years), diagnosed with intracranial space occupying lesions, scheduled (ASA I, II, III) for elective supratentorial craniotomy with pre-operative GCS 15/15 were included in the study. With the help of computer generated software, they were randomly divided into 2 groups.

Group R - who would receive scalp block with plain $0.2 \%$ Ropivacaine.

Group D - who would receive scalp block with $0.2 \%$ Ropivacaine plus $8 \mathrm{mg}$ Dexamethasone.

Patients who underwent craniotomy previously, patients diagnosed with hypertension, diabetes mellitus, coagulopathies, peptic ulcer disease and allergy to local anaesthetics were excluded from the study.

On the day of surgery, patients were pre-medicated with oral Diazepam and Metoclopramide. Pulse oximetry, 5-lead ECG and invasive blood pressure were monitored from time of pre-oxygenation and ET CO2, nasal temperature, urine output, random blood sugar were monitored after induction. Induction was done with $5 \mathrm{mg} / \mathrm{kg}$ Thiopentone Sodium, 2 $\mathrm{mcg} / \mathrm{kg}$ Fentanyl and $0.1 \mathrm{mg} / \mathrm{kg}$ Vecuronium. After oral intubation with cuffed endotracheal tube, anaesthesia was maintained with Isoflurane 0.8-0.9 MAC, Nitrous oxide and Oxygen in 5:3 ratio. Muscle relaxation was maintained. Vecuronium given intermittently every 15 minutes. Any rise in $\mathrm{BP}$ or heart rate in response to surgical stimulus was treated with Propofol $1 \mathrm{mcg} / \mathrm{kg}$ bolus. After induction, a scalp nerve block was performed in patients of Group $\mathrm{R}$ with a mixture of $40 \mathrm{~mL}$ of $0.2 \%$ Ropivacaine and $2 \mathrm{~mL}$ saline and in patients of Group D, a mixture of $40 \mathrm{~mL}$ of $0.2 \%$ Ropivacaine and $2 \mathrm{~mL}$ of Dexamethasone. Supraorbital, Supratrochlear, Zygomaticotemporal, Lesser and Greater occipital nerves were blocked with 22-G spinal needle. Pulse rate and BP were noted at induction, 5 minutes after intubation, insertion of cranial pins, skin incision, craniotomy and dural opening. If there was a significant rise in heart rate ( $>10$ beats/min from baseline) or rise in MAP (>10 $\mathrm{mmHg}$ ) prior to stimulus, block was considered inadequate. Significant elevation in heart rate or BP if any were noted during dural closure, closing of bone flap, skin suturing and removal of pins. The total dose of Propofol and Fentanyl used intraoperatively was also noted. The time from discontinuation of Isoflurane to extubation was noted. All patients were observed in ICU for at least 24 hours. The Glasgow Coma Scale and Visual Analogue Scale were noted at $1,4,8,12$ and 24 hours post-operatively. Any complications like hyperglycaemia, PONV, seizures, reoperation and postoperative ventilation were noted.

\section{RESULTS}

180 adult patients of ASA Grade I to III were included in this study and were divided into 2 groups of 90 each randomly. The baseline data comparing age, gender, weight, surgery and preoperative VAS score were tabulated.

\begin{tabular}{|c|c|c|}
\hline Data & $\begin{array}{c}\text { Group R } \\
(n=90)\end{array}$ & $\begin{array}{c}\text { Group D } \\
(n=90)\end{array}$ \\
\hline Male & $54(60 \%)$ & $48(53.3 \%)$ \\
\hline Female & $36(40 \%)$ & $42(46.7 \%)$ \\
\hline Age (Mean \pm SD) & $\begin{array}{c}40.2 \\
( \pm 10.99) \\
\text { years }\end{array}$ & $\begin{array}{c}42.26 \\
( \pm 12.20) \\
\text { years }\end{array}$ \\
\hline Weight (Mean \pm SD) & $\begin{array}{c}61.33 \\
( \pm 10.01) \mathrm{kgs}\end{array}$ & $\begin{array}{c}59.24 \\
( \pm 10.45) \mathrm{kgs}\end{array}$ \\
\hline $\begin{array}{l}\text { Surgery Duration } \\
\quad \text { (Mean } \pm \text { SD) }\end{array}$ & $\begin{array}{c}292.6 \\
( \pm 89.51) \\
\text { minutes } \\
\end{array}$ & $\begin{array}{c}285 \\
( \pm 78.99) \\
\text { minutes } \\
\end{array}$ \\
\hline Pre-op VAS & 4.06 & 3.74 \\
\hline $\begin{array}{l}\text { Patients with post-op } \\
\text { sugar }>200 \mathrm{mg} / \mathrm{dL}\end{array}$ & $2(2.2 \%)$ & 0 \\
\hline
\end{tabular}

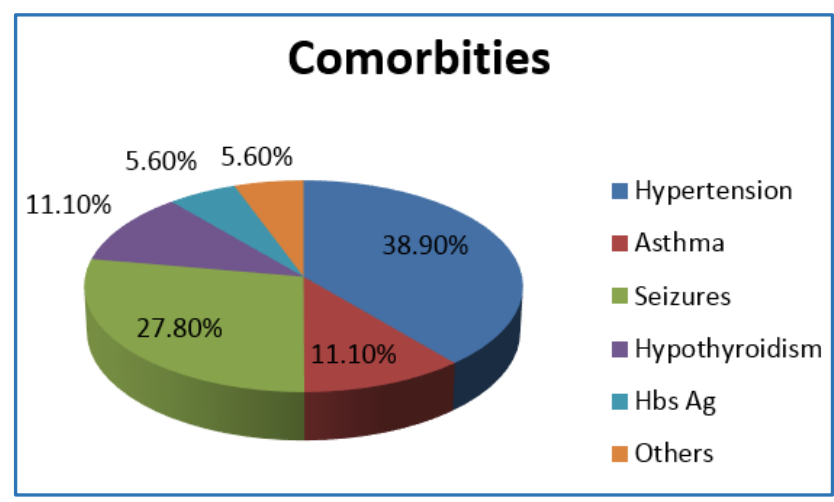

Group R

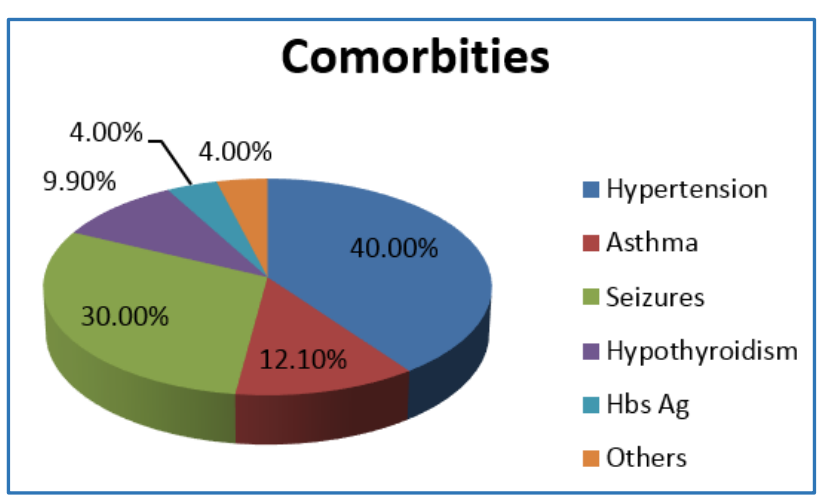

Group D 
Among the ASA II and III patients in each group, the comorbidities were mainly hypertension followed by seizures, asthma, hypothyroidism and HBsAG. Other category included CVA and ischaemic heart disease.

\begin{tabular}{|c|c|c|}
\hline Site & Group R & Group D \\
\hline Frontal & 24 & 22 \\
\hline Parietal & 22 & 24 \\
\hline Temporal & 16 & 12 \\
\hline Parieto-occipital & 2 & 0 \\
\hline Fronto-temporal & 10 & 12 \\
\hline Fronto-parietal & 12 & 10 \\
\hline Fronto-parieto-temporal & 0 & 2 \\
\hline \multicolumn{2}{|c|}{ Table 2: Sites of Craniotomy in the Two Groups } \\
\hline
\end{tabular}

The mean duration of scalp nerve block in Group $\mathrm{R}$ was $763.8 \pm 592$ minutes and in Group D it was $827.8 \pm 525$ minutes. The difference was not statistically significant ( $p>0.05$ ).

\begin{tabular}{|c|c|c|c|}
\hline Parameter & $\begin{array}{c}\text { Group R } \\
\text { (min) }\end{array}$ & $\begin{array}{c}\text { Group D } \\
\text { (min) }\end{array}$ & $\begin{array}{c}\mathbf{p} \\
\text { Value }\end{array}$ \\
\hline $\begin{array}{c}\text { Mean duration of } \\
\text { scalp nerve block }\end{array}$ & $763.8 \pm 592$ & $827.8 \pm 525$ & 0.444 \\
\hline \multicolumn{3}{|c|}{ Table 3: Mean Duration of Scalp Nerve Block }
\end{tabular}

Table 3: Mean Duration of Scalp Nerve Block

Additional intra-op anaesthetic requirement was measured in terms of Fentanyl $(\mu / \mathrm{kg})$ and Propofol $(\mathrm{mg} / \mathrm{kg})$ used to attenuate heart rate and blood pressure. There was no statistically significant difference in intraoperative Fentanyl requirement, but higher dose of Propofol was required. (P $<0.005)$. Time to emergence from anaesthesia and incidence of PONV was similar in the two groups.

The median VAS score prior to administration of the first post-operative rescue analgesic was compared between the two groups to assess the quality of the scalp nerve block. The median VAS score in Group D was 6.0 (Interquartile range 4-9) and in Group R was 7.0 (Interquartile range 5-10). Although, it appears that median VAS score was lower in Group D, the result was not statistically significant ( $p>0.05$ ).

Out of the 10 patients who underwent temporal craniotomy in Group R, failed blocks occurred in 6 patients. However, failed blocks occurred in 2 patients who underwent temporal craniotomy patients in Group D.

\begin{tabular}{|c|c|c|c|}
\hline Parameter & Group R & Group D & $\begin{array}{c}\text { P } \\
\text { value }\end{array}$ \\
\hline $\begin{array}{c}\text { Median intra-op } \\
\text { Fentanyl dose } \\
(\mu \backslash \mathrm{kg})(\mathrm{IQR})\end{array}$ & $\begin{array}{c}2.00 \\
(2.00-3.00)\end{array}$ & $\begin{array}{c}2.00 \\
(2.00-3.00)\end{array}$ & 0.775 \\
\hline $\begin{array}{c}\text { Median } \\
\text { Propofol dose } \\
\text { (mg } \backslash \mathrm{kg})(\mathrm{IQR})\end{array}$ & $2.0(1.0-2.0)$ & $0.47(0-0.75)$ & 0.015 \\
\hline $\begin{array}{c}\text { Median time to } \\
\text { emergence } \\
\text { (Minutes) }\end{array}$ & $\begin{array}{c}15.00 \\
(9.25-20.00)\end{array}$ & $\begin{array}{c}13.00 \\
(10.00-15.50)\end{array}$ & 0.497 \\
\hline $\begin{array}{c}\text { Patients } \\
\text { requiring } \\
\text { Propofol (\%) }\end{array}$ & $42(46.7 \%)$ & $16(17.8 \%)$ & 0.003 \\
\hline $\begin{array}{c}\text { Median VAS } \\
\text { scores prior to } \\
\text { first dose of } \\
\text { rescue analgesia }\end{array}$ & $7.0(5-10)$ & $6.0(4-9)$ & 0.181 \\
\hline $\begin{array}{c}\text { Post-operative } \\
\text { nausea vomiting } \\
\text { (\%) }\end{array}$ & $4(4.4 \%)$ & $4(4.5 \%)$ & 1.000 \\
\hline $\begin{array}{c}\text { Table 4: Intra-op Anaesthetic Requirement, } \\
\text { Median Time of Emergence, Post-Op. } \\
\text { VAS Scores and Incidence of PONV }\end{array}$ \\
\hline
\end{tabular}

It was noted that no patient suffered from peptic ulcer bleed in either groups. Two patients in Group R had RBS >200 $\mathrm{mg} \%$ post-operatively in ICU and needed insulin till discharge. Two patients recorded intraoperative RBS $>200 \mathrm{mg} \%$, which normalised at the conclusion of surgery and remained so in postoperative period.

\section{DISCUSSION}

More than $80 \%$ of brain tumours in adults are supratentorial; the commonest being gliomas, meningiomas and pituitary adenomas (Central Brain Tumour Registry - USA). Analgesia in neurosurgical patients is a unique challenge, because on one hand inadequate analgesia causes agitation, hypertension and vomiting, which increase the risk of intracranial bleed. On the other hand, narcotic analgesics may cause respiratory depression and hypercapnia, which result in cerebral vasodilatation and increased ICP. Uncontrolled pain has systemic side effects that may directly affect patient outcome.[4] Also, application of Mayfield pins through the layers of the scalp into the periosteum, locked at a pressure of $30 \mathrm{lbs}$ and bearing the entire weight of the scalp throughout the surgery is also very painful procedure and needs to be controlled by either local or systemic methods. [2] Zohry et al showed that local $2 \%$ Lidocaine infiltration is more useful than intravenous Fentanyl in terms of ameliorating haemodynamic changes.[6]

Lawan Tuchinda.[7] compared duration of scalp nerve block with $0.5 \%$ Bupivacaine and $0.25 \%$ Bupivacaine prior to insertion of cranial pins, but excluded the duration of surgery. This may explain the shorter duration of the scalp nerve block reported by Lawan Tuchinda. Nguyen et al[8] studied 30 cases of supratentorial craniotomy, which were randomly allocated to receive either $0.75 \%$ Ropivacaine or saline in scalp nerve block at the conclusion of surgery prior to extubation. Visual analogue scale scores were higher in saline group compared to Ropivacaine group over a 48-hour period, but the two groups did not differ with respect to the total dose of intravenous Fentanyl administered for post-operative pain relief or the time duration prior to first dose of postoperative analgesic.

Lawan Tuchinda. ${ }^{[7]}$ showed a decrease in intraoperative Fentanyl requirement in patients who received $0.5 \%$ and $0.25 \%$ Bupivacaine in scalp nerve block compared to those who received normal saline in scalp nerve block. Gazoni.[9] showed no difference in mean concentration of intraoperative Sevoflurane and Fentanyl requirement in patients who received pre-incision scalp nerve block with $0.5 \%$ Ropivacaine to patients who received normal saline. It is apparent that temporal craniotomy was associated with higher incidence of failed blocks due to more pain when temporalis muscle is split RBS was measured with handheld glucometer intraoperatively and postoperatively in ICU, because of concern that Dexamethasone may be absorbed systematically owing to high vascularity of the scalp. Systematically absorbed Dexamethasone could result in steroid related complications like upper GI bleed and hyperglycaemia.[10]

\section{CONCLUSION}

Thus, addition of $8 \mathrm{mg}$ Dexamethasone to $0.2 \%$ Ropivacaine in scalp nerve block after induction of general anaesthesia for patients undergoing supratentorial craniotomy for intracranial space occupying lesion does not prolong the duration compared to plain $0.2 \%$ Ropivacaine nor does 
decrease intraoperative Fentanyl requirements. There was no difference in the time of emergence from anaesthesia or incidence of PONV.

\section{REFERENCES}

1. Foroohar M, Macdonald RL, Roth S, et al. Intraoperative variables and early outcome after aneurysm surgery. Surg Neurol 2000;54(4):304-15.

2. Levin R, Hesselvik JF, Kourtopoulos H, et al. Local anaesthesia prevents hypertension following application of the Mayfield skull-pin head holder. Acta Anaesthesiol Scand 1989;33(4):277-9.

3. De Benedittis G, Lorenzetti A, Migliore M, et al. Postoperative pain in neurosurgery: a pilot study in brain surgery. Neurosurgery 1996;38(3):466-9.

4. Ortiz-Cardona J, Bendo AA. Perioperative pain management in the neurosurgical patient. Anesthesiol Clin 2007;25(3):655-74.

5. Girvin JP. Neurosurgical considerations and general methods for craniotomy under local anaesthesia. Int Anesthesiol Clin 1986;24(3):89-114.
6. Zohry G, Hosny H, Nabil D, et al. Lidocaine infiltration versus intravenous fentanyl for preventing the hemodynamic response to pin insertion in craniotomy patients: a transcranial Doppler study. Egypt J Neurol Psychiatr Neurosurg 2006;43:41-8.

7. Tuchinda L, Somboonviboon W, Supbornsug K, et al. Bupivacaine in scalp nerve block. Asian Biomedicine 2010;4(2):243-51.

8. Nguyen A, Girard F, Boudreault D, et al. Scalp nerve block decreases pain after craniotomy. Anesth Analg 2001;93(5):1272-6.

9. Gazoni FM, Pouratian N, Nemergut EC. Effect of ropivacaine skull block on perioperative outcomes in patients with supratentorial brain tumors and comparison with remifentanil: a pilot study. J Neuro Surg 2008;109(1):44-9.

10. Lukins MB, Manninen PH. Hyperglycemia in patients administered dexamethasone for craniotomy. Anesth Analg 2005;100(4):1129-33. 